\title{
SLIP PROCESSES AND FRACTURE IN IRON CRYSTALS
}

\author{
V. Pelikán ${ }^{1, \mathrm{a}}$, P. Hora ${ }^{1, \mathrm{~b}}$, A. Machová, ${ }^{2, \mathrm{c}}$, M. Landa ${ }^{2, \mathrm{~d}}$ \\ ${ }^{1}$ CDM-Institute of Thermomechanics AS CR, Pilsen, 30114 Veleslavínova 11 \\ ${ }^{2}$ Institute of Thermomechanics AS CR, Prague 8, 18200 Dolejškova 5 \\ a pelikan@cdm.it.cas.cz, ${ }^{\mathrm{b}}$ hora@cdm.it.cas.cz, ${ }^{\mathrm{c}}$ machova@it.cas.cz, ${ }^{\mathrm{d}} \mathrm{ml} @$ it.cas.cz
}

\section{Summary}

The brittle-ductile behavior of cracks has long been an area of intensive study. In particular, body centered cubic (bcc) iron has been studied often in the recent past in the framework of continuum (e.g. Rice et al. [1-3]) and atomistic models (e.g. Mullins et al. [4-8]), and as well in experiments (e.g. Marsh et al. [9], Šmida and Bošanský [10]) due to the structural steels applications. The models consider usually plane strain conditions (2D) along the crack front and temperature of $0 \mathrm{~K}$. However, free sample surface (where plane stress conditions are expected in the normal direction) may influence the ductile-brittle behavior, as well as the thermal atomic motion. Such studies require 3D atomistic simulations.

This contribution is devoted to crack simulations by molecular dynamic (MD) technique in 3D bcc iron crystals. We use our new MD code for parallel processing in MPI. Interatomic interactions in bcc iron are described using N-body potentials of Finnis-Sinclair type (Ackland et al. [11, 12]). The 3D codes have been tested in perfect samples under simple uni-axial tension and in thermal simulations. The simulated thermal expansion in bcc iron agrees well with experimental data (see Machová [13]), as well as the phonon frequency spectra $[11,12]$.

In crack simulations we consider a central pre-existing Griffith (through) crack loaded in tension mode I. The relatively long crack is embedded in a thin bec iron crystal having the basic cubic $\{100\}$ orientation. The crack is introduced by removing part of atoms from the central plane, i.e. its initial blunting corresponds to the lattice parameter. Crack surface lies on a (001) plane, crack front is oriented along the [010] direction, and the direction of the potential crack extension is [100]. The interatomic interactions across the free crack faces are not allowed. Surface relaxation has been performed before a loading to avoid its influence on crack tip processes.

We performed the 3D crack simulations at temperatures of $0 \mathrm{~K}$ and $300 \mathrm{~K}$. At these temperatures, the samples were loaded symmetrically in the $<001>$ directions by prescribing external forces $F_{\text {ext }}$ distributed homogeneously at individual atoms lying in several surface layers, similar to [11]. The samples were loaded slowly, gradually in time. While at the temperature of $0 \mathrm{~K}$ brittle crack initiation has been observed, at $300 \mathrm{~K}$ dislocation emission and slip processes on $\{110\}$ and $\{112\}$ planes have been detected. The slip processes start at the free sample surfaces, which is in agreement with our stress analysis and MD simulations by Zhou et al. [14]. The process begins on $\{110\}$ planes via emission of a curved dislocation ( $\sim$ quarter circle loop) from the corners, where the crack penetrates the free sample surface. We further show that the slip processes on the inclined $\{110\}$ planes cause crack tip blunting and hinders crack growth. The slip processes on the oblique $\{112\}$ planes make jogs in the crack front and enable a slow plastic crack growth. 
Our results are in agreement with continuum predictions that the microscopic processes at the crack front generally depend also on the mutual orientation of the crack and accessible slip systems (see e.g. Pokluda and Šandera [15]).

\section{Acknowledgements}

The work was supported by the Grant Agency at Academy of Sciences of the Czech Republic under a grant IAA2076201. The authors thank Dr. F. Kroupa, Dr. V. Paidar and Alena Spielmannová for very helpful discussions.

\section{References}

1. Rice, J.R., J. Mech. Phys. Solids, vol. 40, 239-271, 1992

2. Beltz, G.E. and Fisher, L.L., In Multiscale deformation and fracture in materials and structures, edited by T.J. Chuang and J.W. Rudnicki, Kluwer, Boston, 2001, 237-242.

3. Argon, A.S., Xu, G. and Ortiz, M., In Fracture-Instability, Dynamics, Scaling, and Ductile/Brittle Behavior, edited by R.L.B. Selinger et al., Materials Research Society, vol. 409, Pittsburgh, 1996, 29-44

4. Mullins, M. and Dokainish, M.A., Phil. Mag. A, vol.46, 771-787, 1982

5. Kohlhoff, S., Gumbsh, P. and Fishmeister, H., Phil. Mag. A, vol. 64, 851-878, 1991

6. Shastry, V. and Farkas, D., Modelling Simul. Mater. Sci., vol. 4, 473-492, 1996

7. Machová, A., Beltz, G.E. and Chang, M., Modelling Simul. Mater. Sci. Eng., vol. 7, 949-974, 1999

8. Beltz, G.E. and Machová, A., Scripta Materialia, vol. 50, 483-487, 2004

9. Marsch, P.G., Zielinski, W., Huang, H. and Gerberich, W., Acta metall. mater., vol. 40, 2883-2894, 1992

10. Šmida, T. and Bošanský, J., Materials Sci. Eng. A, vol. 287, 107-115, 2000

11. Machová, A. and Ackland, G.J., Modelling Simul. Mater. Sci. Eng., vol. 6, 521-542, 1998

12. Ackland, G.J., Bacon, D.J., Calder, A.F. and Harry, T., Phil. Mag. A, vol. 75, 713-732, 1997

13. Machová, A., Computational Materials Science, vol. 24, 535-543, 2002

14. Zhou, S.J., Beazley, D.M., Lomdahl, P.S., Voter, A.F. and Hollian, B.L., In Advances in fracture research, edited by B.L. Karihaloo et al., Pergamon, New York, 1997, 30853094

15. Pokluda, J. and Šandera, P., Metall. Mater., vol. 33, 375-383, 1995 